\title{
The essentials of medical consultation
}

An editorial by Intensive Care Medicine from $2017^{1}$ predicted that, by 2050, hospitals will be smaller with lots of ICU beds, and robots will do many medical tasks. The authors foretold that there will still be some disciplines where human contact is very important, like... pediatrics. This gives us the green light to bring to mind the little details of pediatric office visits.

First of all, we have to listen. "Physicians know how to talk, but not how to listen," stated Nanni Moretti in his movie Caro Diario. Having open ears to listen to the patient's description of symptoms, dates, medication, and "folk medicine" is usually the key to unlock the door to diagnosis. If the child is able to describe them, we should give importance to his/her narration. From the beginning, we should pay attention to the quality of crying, the tone of voice, difficult breathing, and the type of cough.

Then, we have to look. Before taking out the tongue depressor, we should look at the child. Detect if he/she is attentive or lethargic, irritable or fussy. What is his/her muscle tone? Skin color? Breathing? If we fail to do this before placing our cold stethoscope on the child's chest, he/she will probably start crying and we will miss a valuable chance to diagnose pneumonia. Before receiving an X-ray showing condensation to document pneumonia, there are other data, in plain sight, that could anticipate it.

Then, there is touch. The 2009 flu epidemics left a "positive consequence": the popularization of alcohol hand sanitizers. They are useful to disinfect our hands even when the nearest sink of the primary health care center (PHCC) is 65 feet away from our office. At present, there are no excuses to avoid touching the patient.

We have to feel the liver in a child who is receiving rapid volume expansion with intravenous fluids for septic shock; to let the splenic pole approach our fingers in a baby with a congenital infection; to use our hands to open the hips at each visit and until the baby starts walking; or to feel a lump under a painful erythema.

We have to roll the patient's lips and check for sores that, if present, may prevent us from giving antibiotics to a child who has pharyngitis and fever. And we have to look for ascending testis in a boy by making him sit in the tailor's seat position. When an infant arrives to the Emergency Department vomiting and crying in pain or, by contrast, if the infant is floppy, we should not fail to insert a finger (the little finger will do) in the baby's rectum. The rectal examination is part of the visit and pediatricians should not "outsource" this task. The rectal examination helps to better feel an abdomen that raises doubts.

And even if it is evident that the reason for consultation is an emotional problem, never fail to touch the patient. Our hands may calm down an upset child, without turning ourselves into a "faith healer."

We also have to sniff. Using the sense of smell will allow us to detect ketotic breath in a patient who vomits frequently; a putrid smell in a child who put foam rubber in his/her nose; foul-smelling stools caused by malabsorption; the smell of alcohol, tobacco or marijuana in an adolescent at risk; and the smell of smoke in a child whose family lacks a heater to warm their house in the slums.

Everyone has different tastes. Although we may try it, we have to admit that we have never been able to diagnose cystic fibrosis of the pancreas based on salty sweat. But we may use our tongue to identify bitter drugs and replace them with more likable alternatives and, if there is no other option, advise caregivers to put ice on the child's tongue in advance to numb the taste buds.

Using tools. We have to aid the five senses. Pediatricians usually brag and complain at the same time: "We use no equipment!" We may not use complex devices, but it is not true that we do not need tools.

When pediatric medical residents go to work at PHCCs, they always bring their own stethoscopes, although even in the more deprived locations, there is always a binaural stethoscope. What they usually lack are auriscopes with functioning batteries, adequate infantometers, sphygmomanometers with small cuffs, pharyngeal swabs, disposable tongue depressors, and prescription pads to avoid writing on the back of any piece of paper that may be thrown away. Many of these deprivations were observed in some of the PHCCs where we have worked. The same deprivations that existed when PHCCs were called "dispensaries." For this reason, whenever a physician goes to a private or public clinic, he/ she should take his / her own "tools." We would not trust an electrician who does not have a voltage tester screw driver or pliers. 
And in the end, talk. There is no such thing as mothers who "do not understand;" there are pediatricians who do not use the right words. If the family does not understand, explanations should be given in a more accessible language, using examples and drawings. Talking very loudly will not make a poor mother improve her attention; it is most likely that, rather than being deaf, her level of education is low.

However, in the case of severely-ill children, the parents may "choose" not to understand the bad news they are receiving. Recognizing this situation is important to include other family members in the conversation.

Pediatricians should speak the necessary; parents want the best advice, not a physician who can prove how much he/she knows. We have to describe the "warning signs" so that the family knows when to ask for an earlier appointment, but we also have to explain the expected progress of the disease so as to prevent unnecessary visits to the Emergency Department.

Before making a diagnosis, we have to take our time. When a child has a skin condition, the first question parents ask is "What is it?" It seems that they think that anything that is visible can be diagnosed rapidly. When faced with a dubious exanthema, let us not fall in the "immediacy trap!" There is no need to rush. A good trick here is to place a thermometer in the child's armpit. In this case, parents usually wait and we will gain 4 valuable minutes to think.

Many times, it is impossible to make a diagnosis based on early symptoms. Except in the case of critically-ill patients, physicians should take the time to see how the child progresses and, in general, parents will understand if you explain this and ask them to make a new appointment.

And let us not forget prejudices. Those of patients and our own. Carlos Gianantonio recommended, as part of the office visit, to hear the family's hypothesis on what was wrong with the child. Regardless of the accuracy of the pediatrician's presumptive diagnosis, he/she should prove to parents that his/her hypothesis is better than theirs. This way, all indications will be better accepted.
As pediatricians, we are vulnerable to our own prejudice. Lawrence Nazarian, the former editor of Pediatrics in Review, used to say that young pediatricians who had just completed their internship program would think that any infant with a fever probably had sepsis and that any child with peculiar traits had a weird syndrome, even though the parents shared the same traits. This is understandable in those who spent 4 years seeing children who were actually severely-ill. However, a pediatrician who has spent decades examining patients who are healthy or have selflimited conditions develops the prejudice that "it is probably nothing serious." Most of the times it is not, but sometimes, when you less expect it, a child who has grown up healthy suddenly develops diabetes, cancer, or depression and bumps into an experienced pediatrician off guard.

Mixing older and younger pediatricians is definitely a satisfying and beneficial association for all, especially for children.

In summary, the essentials of pediatric consultation include a trained pediatrician who is capable of putting the five senses to work. In turn, it is critical to promote strategies aimed at making sure all children across Argentina are seen by pediatricians.

\section{Acknowledgments}

I would like to thank all those who started their journey in pediatrics at Hospital de Niños de Santa Fe. In loving memory of pediatricians Federico Milia, M.D., Ángel Spedaletti, M.D., and Abel Argento, M.D.

Juan Carlos Beltramino, Pediatrician Former Director of Teaching and Research of Hospital de Niños “Dr. O. Alassia" of Santa Fe.

http: / / dx.doi.org/ 10.5546/aap.2018.eng.236

To cite: Beltramino JC. The essentials of medical consultation. Arch Argent Pediatr 2018;116(4):236-237.

\section{REFERENCE}

1. VincentJL, Slutsky AS, Gattinoni L. Intensive care medicine in 2050: the future of ICU treatments. Intensive Care Med 2017; 43(9):1401-2. 